\title{
Microstructural Refinement of Cast Ti48Al2W0.5Si Alloy by Static Heat Treatment
}

\author{
E. Evangelista, W.J. Zhang, L. Francesconi, E. Cerri and S. Spigarelli \\ Department of Mechanics, University of Ancona, 1-60131 Ancona, Italy
}

\begin{abstract}
The microstructure of the massive transformed Ti48A12W0.5Si alloy was studied during tempering in the temperature range of $1100-1360^{\circ} \mathrm{C}$. A fine fullylamellar microstructure with the grain size of 170-220 $\mu \mathrm{m}$ was developed after tempering in the single alpha field. While a duplex structure comprising equiaxed $\gamma$ grains and lamellar colonies was obtained at 1300$1340^{\circ} \mathrm{C}$, a dual structure of fine $\gamma$ grains and $\alpha 2(\beta)$ plates was observed at $1250^{\circ} \mathrm{C}$. After tempering at $1100^{\circ} \mathrm{C}$, fine and dense $\alpha_{2}$ and $\beta$ particles were precipitated on the massive $\gamma$ matrix. Compression tests confirmed that the properties of cast Ti48Al2W0.5Si alloy are considerably improved by quenching/ tempering processes.
\end{abstract}

\section{INTRODUCTION}

Recently, considerable studies have focused on optimizing the properties of TiAl-base .alloys by microstructure control through thermo-mechanical treatments and alloy modification. Depending on the heat treatment, a duplex, a near-fully-lamellar or a fully-lamellar microstructure can be obtained $/ 1,2 /$. The lamellar structure is generally tougher than the fine duplex one, while the latter is more ductile. However, the ductility of the lamellar structure can be improved by refining its colony size. A fine fully-lamellar microstructure is thus accepted as the most promising candidate, because it exhibits a good combination of ductility, high temperature strength and creep resistance $/ 2,3 /$. By appropriate thermo-mechanical treatment, a lamellar structure with a colony size of 100-300 $\mu \mathrm{m}$ can be produced.

Compared to the wrought or powder-metallurgical route, investment casting may be the most feasible and cost-effective approach for the manufacture of near-netshape components, such as blades and vanes $/ 4,5 /$. The key shortcoming of cast TiAl alloys is the residual coarse ingot microstructure, which is harmful to the performance of the final products. Therefore, it is of the utmost importance to find an approach to refine the microstructure of cast TiAl-base components.

The quenching/tempering process is a wellestablished heat treatment for most high-alloy steels. Upon tempering, the toughness of the as-quenched martensitic microstructure is greatly improved by the formation of various types and distribution of carbides; in this way, a wide variety of microstructure and properties can be achieved to meet industrial requirements. In a similar case, a massive transformed microstructure with the supersaturated $\gamma$ phase containing a high density of defects has been observed by rapid cooling of TiAl-base alloys from the hightemperature $\alpha$ phase field $16,7 /$. Therefore, it is interesting to investigate the possibility of refining the microstructure of TiAl-base alloy by quenching/tempering processes, instead of the conventional thermo-mechanical routes. In this paper, the effect of tempering on the microstructure and ductility of a cast Ti48Al2W0.5Si alloy was investigated after massive transformation. 


\section{EXPERIMENTAL}

The alloy used in this investigation was provided by ABB Power Generation Ltd. In cast bars with a diameter of $16 \mathrm{~mm}$ under US patent 5286443. The composition of the alloy was as follows: $\mathrm{Al}=31.5-32.3$, $\mathrm{W}=8.68-8.98, \mathrm{Si}=0.2-0.3, \mathrm{O}=0.063-0.077, \mathrm{~N}=$ $0.0050-0.0061, \mathrm{H}=0.0012-0.0050, \mathrm{Ti}=$ balance. The material was hipped at $1185^{\circ} \mathrm{C} / 172 \mathrm{MPa} / 3 \mathrm{~h}$ and then heat-treated at $1302^{\circ} \mathrm{C} / 20 \mathrm{~h}(\mathrm{Ar}) / \mathrm{GFC}+913^{\circ} \mathrm{C} / 4$ $\mathrm{h}$ (Ar)/GFC (GFC: gas fan cooling). Samples for heat treatment $(8 \times \phi 16 \mathrm{~m})$ were sectioned from the bars and protected by a high-temperature glass-alumina coating. The samples were first homogenized in the single $\alpha$ region, namely $1375^{\circ} \mathrm{C}$, for $45 \mathrm{~min}$, water quenched, and then tempered at $1100-1360^{\circ} \mathrm{C}$, followed by controlled furnace cooling $\left(10 \mathrm{~K} / \mathrm{min}\right.$ to $1100^{\circ} \mathrm{C}$ and then air cooled) to transform the high-temperature $\alpha$ into the lamellar structure. Examination of the microstructure was performed using optical microscopy with an image analyzer and by transmission electron microscopy (TEM). TEM foils were thinned by mechanically polishing to about $100 \mu \mathrm{m}$, and then by twin-jet polishing in a solution of $95 \%$ methanol and $5 \%$ perchloric acid, at $10-15 \mathrm{~V}$ and $-35^{\circ} \mathrm{C} \sim 40^{\circ} \mathrm{C}$. The observations were carried out with a Phillips CM12 TEM at an accelerating voltage of $120 \mathrm{kV}$.
Compression tests were conducted at room temperature on a MTS testing machine at an initial strain rate of 1 $\times 10^{-3} \mathrm{~s}^{-1}$, using $5 \times 5 \times 10 \mathrm{~mm}$ specimens.

\section{RESULTS}

The as-received alloy exhibits a duplex microstructure with a mean grain size of about $100 \mu \mathrm{m}$ (Fig. la). Holding at $1375^{\circ} \mathrm{C} / 45 \mathrm{~min}$ developed a structure of nearly single $\alpha$ grains of about $450 \mu \mathrm{m}$ in size, and less than 1 vol.\% of remnant $\gamma(+\beta)$ phases (Fig. 1b). Water quenching produces a microstructure comprising mottled or dark patchy regions and some light featureless areas (Fig. 2a), which were revealed by TEM to be massive $\gamma\left(\gamma_{m}\right)$ and retained $\alpha_{2}$ phase, respectively, in agreement with other authors $/ 6,7 /$. The high density of stacking faults, dislocations and antiphase boundaries were confirmed within the $\gamma_{\mathrm{m}}$ grains (Fig. 2b).

The microstructure variation of the quenched samples after tempering at temperatures of $1100^{\circ} \mathrm{C}$ $1360^{\circ} \mathrm{C}$ is shown in Fig. 3. The strong dependence of microstructure on the temperature is clearly evident. Tempering at $1100^{\circ} \mathrm{C} / 8 \mathrm{~h}$ leads to the heterogeneous precipitation of very fine particles on prior massive $\gamma$ and retained $\alpha_{2}$ matrix, with the massive morphology
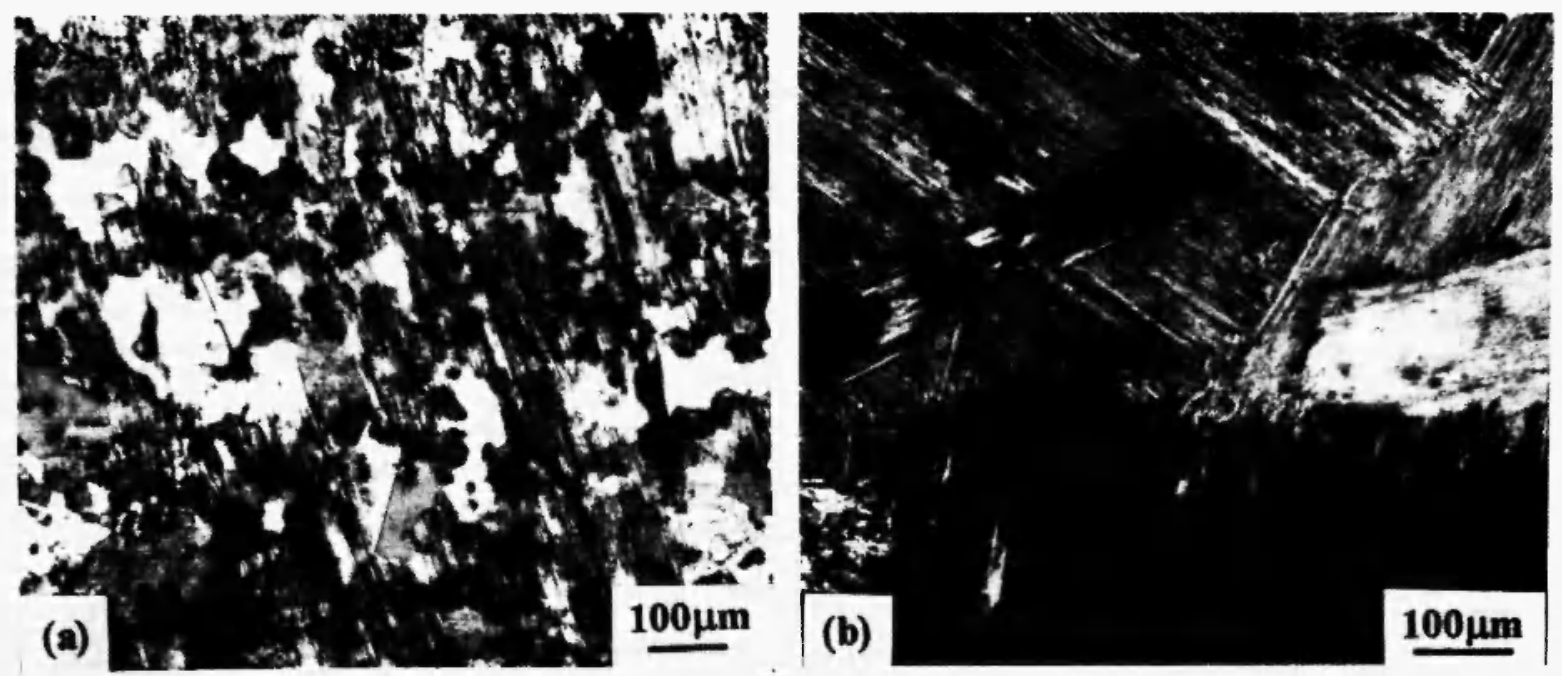

Fig. 1: Optical microstructure of the Ti48Al2W0.5Si alloy (a) as-received and (b) homogenized at $1375^{\circ} \mathrm{C} / 45 \mathrm{~min}$ and controlled furnace cooled. 

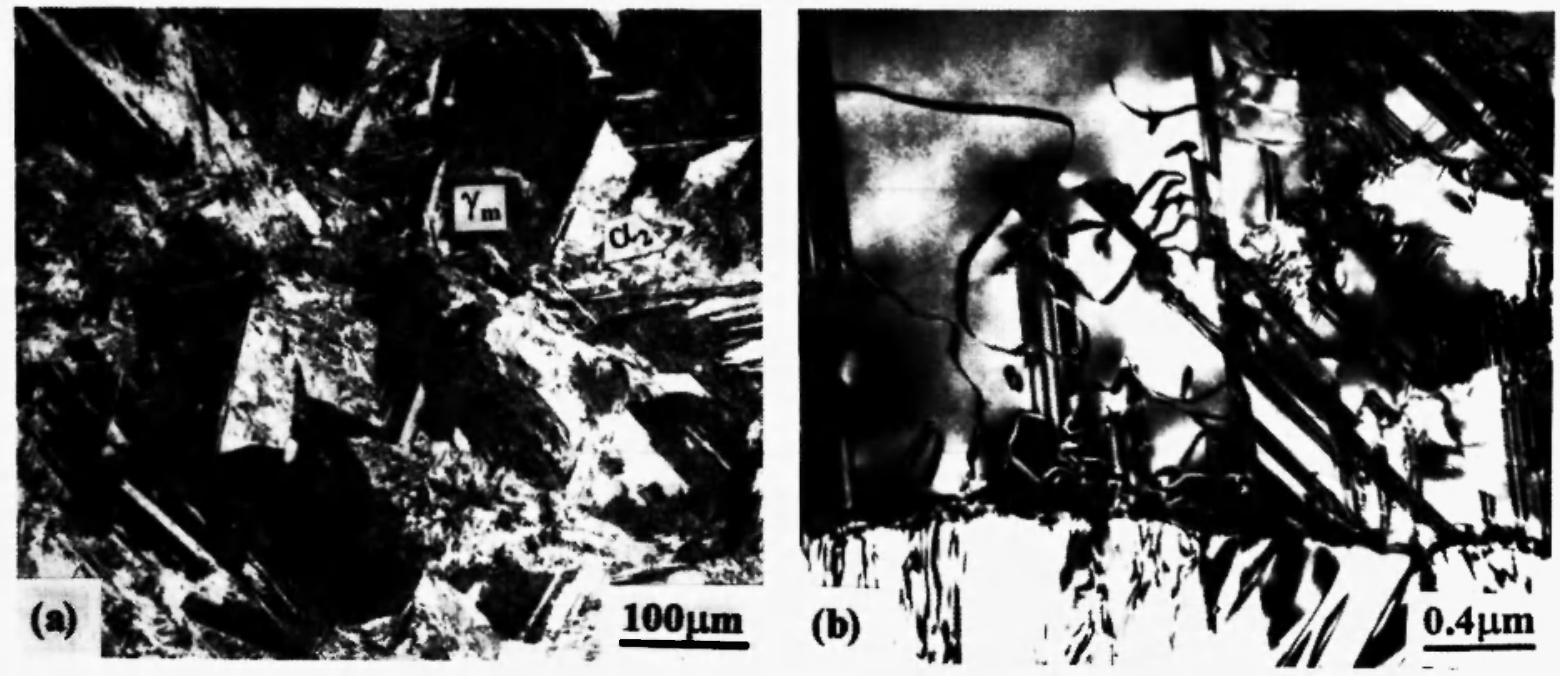

Fig. 2: Optical microstructure of the water-quenched Ti48Al2W0.5Si alloy (a) and TEM micrograph (b) showing the high density of stacking faults, dislocations and antiphase boundaries in massive $\gamma$ region.

still being partially visible (Fig. 3a). The fine precipitates were identified to be $\alpha_{2}$ and $\beta$ phases, preferably formed on grain boundaries and stacking faults (fig. 4a). After $1250^{\circ} \mathrm{C} / 3 \mathrm{~h}$, a dual structure consisting of $\gamma$ grains and about 25 vol.\% of oriented dispersoids was observed (Fig. 3b). TEM observation confirmed that the dispersoids are mostly $\alpha_{2}$ plates or needles, and again some $\beta$ precipitates (Fig. 4b). Increasing the temperature up to $1300^{\circ} \mathrm{C}$, a duplex structure consisting of more than $60 \mathrm{vol} . \%$ of lamellar colony $(70 \mu \mathrm{m})$ and equiaxed $\gamma$ grains was produced (Fig. 3c). Most importantly, a fine fully lamellar microstructure was developed after tempering in the single alpha field (Fig. 3d); the tempered lamellar grain size is shown in Fig. 5 as a function of temperature.

Since the fully-lamellar microstructure is the most promising one for engineering applications, the properties of the fine tempered lamellar structure were compared with those of the as-received and the homogenized ones by compression tests. As can be seen in Fig. 6, the tempered fully-lamellar microstructure exhibits a fracture strain (31.5\%) higher than that of the homogenized (coarse) lamellar structure (22\%) and even of the as-received duplex one $(25 \%)$. The tempered sample also shows a yield strength comparable to that of the duplex structure. These results confirmed that the microstructure and properties of cast
TiAl-base alloy can be significantly improved by static heat treatment, namely, quenching/tempering processes.

\section{DISCUSSION}

The significant finding of this investigation is the possible of refining the microstructure of cast TiAl-base alloy by a static heat treatment, instead of the costly thermo-mechanical process. As can be seen in Fig. 5, tempering the massive transformed Ti46Al2W0.5Si alloy in the single alpha field produces a fully-lamellar microstructure with a mean grain size as fine as 170$220 \mu \mathrm{m}$. This observation suggested that recrystallization has occurred in the water-quenched microstructure during tempering. The driving force for recrystallization is believed to be related to the high density of faults introduced by massive transformation (Fig. 2b), in analogy with the deformation-induced defects in the thermo-mechanically processed (TMP) alloy. The tempered fine fully-lamellar microstructure is expected to have a promising combination of ductility, fracture toughness, and creep resistance as obtained in the TMP alloy /2,3/. The preliminary results in Fig. 6 confirmed the improved properties of the tempered microstructure as compared to the as-received and homogenized alloys. 

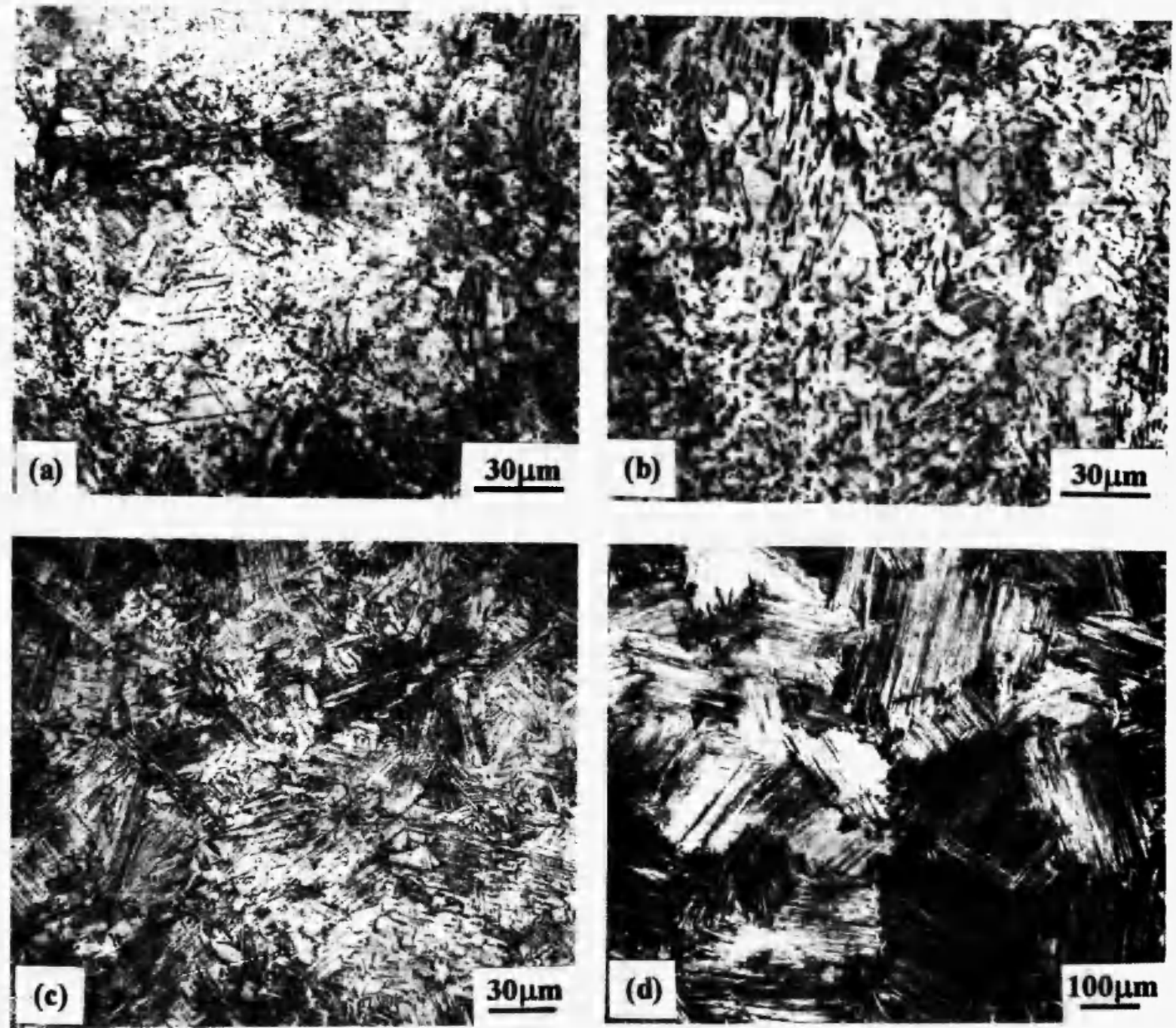

Fig. 3: The microstructure variation of the water-quenched Ti48Al2W0.5Si alloy during tempering at (a) $1100^{\circ} \mathrm{C} / 8$ $\mathrm{h} / \mathrm{CFC}$, (b) $1250^{\circ} \mathrm{C} / 3 \mathrm{~h} / \mathrm{CFC}$, (c) $1300^{\circ} \mathrm{C} / 1 \mathrm{~h} / \mathrm{CFC}$, and (d) slowly heating from $1320^{\circ} \mathrm{C}$ to $1360^{\circ} \mathrm{C}$ (CFC).

The strong effect of temperature on the tempered microstructure can be rationalized on the basis of the $\mathrm{Ti}$-Al phase diagram $/ 8 /$. Tempering at $1300-1360^{\circ} \mathrm{C}$, a duplex microstructure comprising equiaxed $\gamma$ and fine lamellar colony was developed (Fig. 3c); the lamellar structure transformed from the recrystallized hightemperature $\alpha$ grains during controlled furnace cooling. At $1250^{\circ} \mathrm{C}$, the $\alpha$ phase formed as plates or spheroids due to its low volume fraction, and during cooling it transformed into single $\alpha_{2}$ rather than the $\alpha_{2}+\gamma$ lamellar structure because of its low Al concentration, thereby resulting in a dual structure of equiaxed $\gamma$ and $\alpha_{2}$ plates (Fig. 3c). As temperature decreased to $1100^{\circ} \mathrm{C}$, the supersaturated massive structure can only be equilibrated by the precipitation of fine dense $\alpha_{2}$ and $\beta$ particles, due to the poor diffusivity of atoms, akin to the tempered martensite in steel.

Finally, microcracks were observed in the massive transformed microstructure. For practical application, a controlled cooling technique is needed, firstly to limit the thermal residual stress induced during quenching, and secondly to ensure a near-completely transformed massive structure; the partially transformed structure, to some extent, leads to the microstructural inhomogeneity after tempering. 

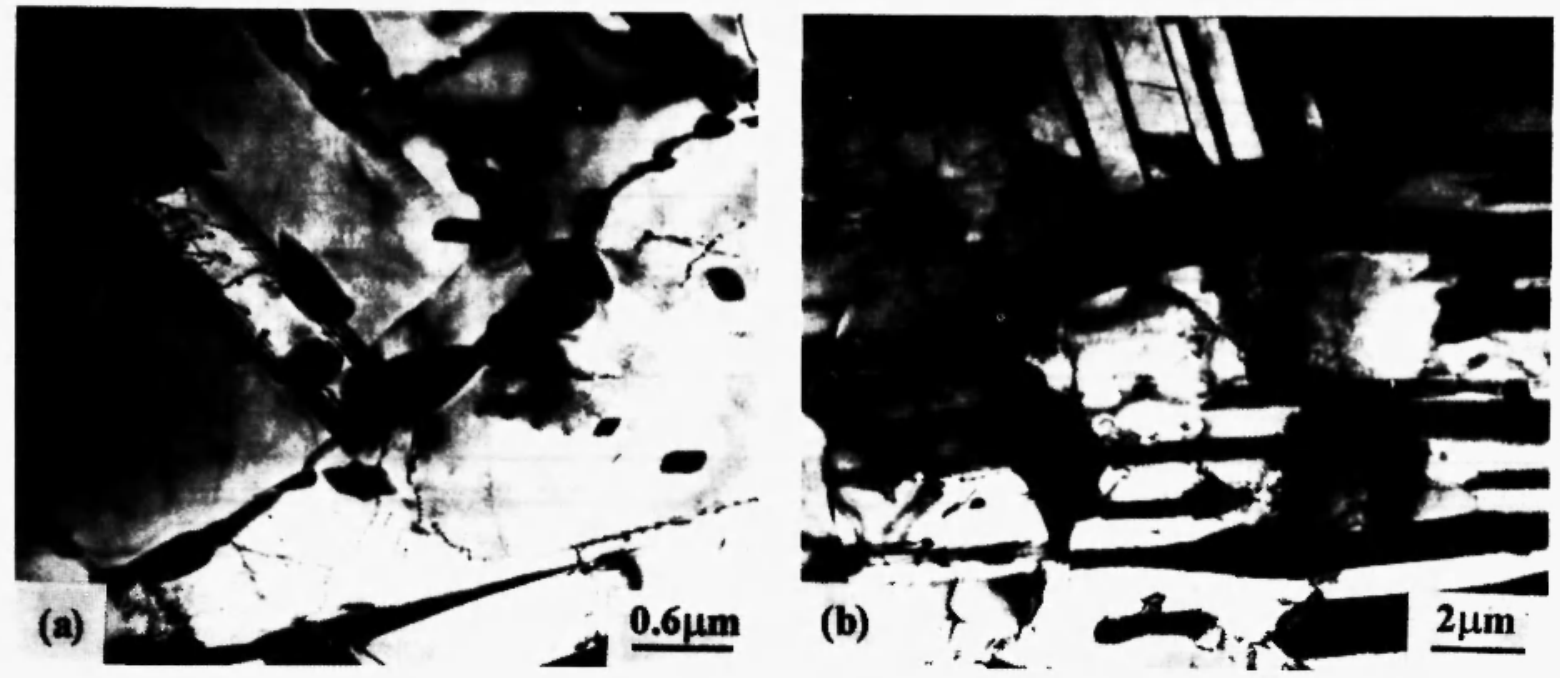

Fig. 4: Bright field TEM micrographs of the Ti48Al2W0.5Si alloy tempered at (a) $1100^{\circ} \mathrm{C} / \mathrm{h} \mathrm{h} / \mathrm{CFC}$ and (b) $1250^{\circ} \mathrm{C} / 3 \mathrm{~h} / \mathrm{CFC}$.

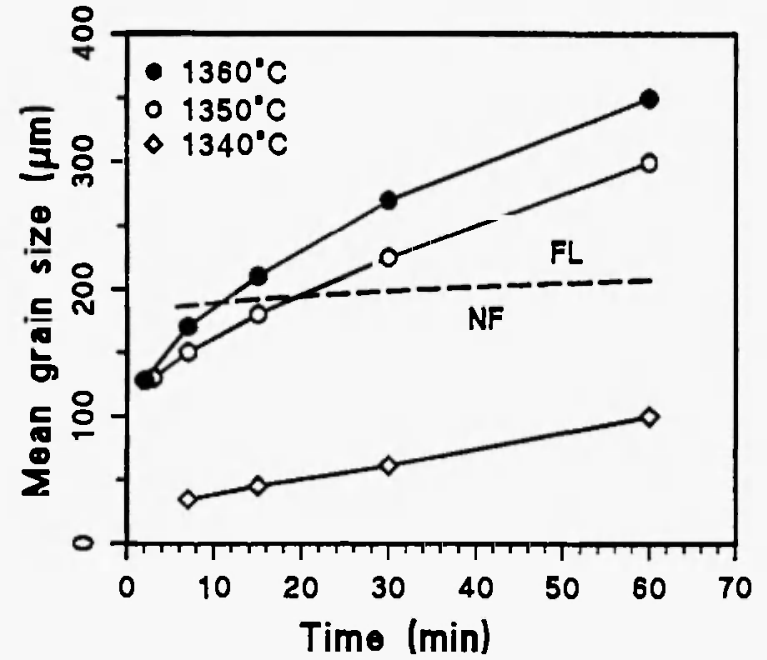

Fig. 5: The lamellar grain size developed in waterquenched Ti48Al2W0.5Si alloy on tempering at $1340 \sim 1360^{\circ} \mathrm{C}$ for $1 \sim 60 \mathrm{~min}$.

\section{SUMMARY}

1. A fine fully-lamellar microstructure (170-220 $\mu \mathrm{m})$ can be developed in cast Ti48Al2W0.5Si alloy by tempering the quenched sample at temperatures above the alpha transus, rather than by the costly thermo-mechanical or powder metallurgical process. The preliminary compression tests

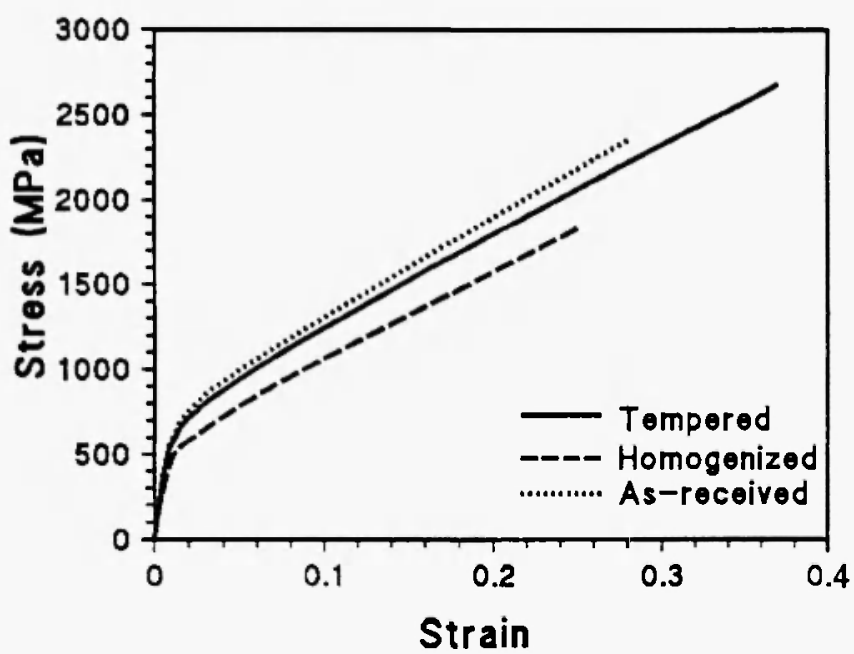

Fig. 6: Room temperature compressive stress-strain curves of the various Ti48Al2W0.5Si microstructures.

As-received: duplex (100 $\mu \mathrm{m})$ (Fig. la); Homogenized: fully-lamellar (460 $\mu \mathrm{m})$ (Fig. lb);

Tempered: fully-lamellar (170 $\mu \mathrm{m})$ (Fig. 3d).

confirmed that the ductility of the tempered lamellar structure is considerably improved, relative to the homogenized fully-lamellar and the as-received duplex alloys. 
2. As tempered below the alpha transus, the microstructure variation is strongly dependent on temperature. A duplex structure comprising equiaxed $\gamma$ and lamellar colonies was obtained at $1300-1340^{\circ} \mathrm{C}$, whereas a dual structure of fine $\gamma$ grains and $\alpha_{2}(\beta)$ plates was produced at $1250^{\circ} \mathrm{C}$, and fine dense $\alpha_{2}$ and $\beta$ precipitates were observed on the massive $\gamma$ matrix at $1100^{\circ} \mathrm{C}$.

\section{ACKNOWLEDGEMENTS}

This research was funded by C.N.R. under grant No. 93.03395.CT11. We are pleased to thank Dr. M. Nazmy (ABB Power Generation Ltd., Baden, Switzerland) for providing the material and for helpful discussions. One author (Zhang) acknowledges the financial support of the European Community, grant No. 93.2009.1L.

\section{REFERENCES}

1. K.S. Chan and Y.W. Kim, Metall. Trans., 23A, 1663-1667 (1992).
2. Y.W. Ki, Mater. Sci. Eng. A, 192/193, 519-533 (1995).

3. Z.J. Pu, J.L. Ma and K.H. Wu, Mat. Res. Soc. Symp. Proc., 364, 487-492 (1995), MRS, Pittsburgh.

4. C.A. Austin and T.J. Kelly, in: Structural Intermetallics, R. Darolia, J.J. Lewandowski, C.T. Liu, P.L. Martin, D.B. Miracle and M.V. Nathal (eds.), Vol. 1, TMS, Warrendale, 1993; pp. 143-150.

5. B. London, D.K. Larsen, Jr., D.A. Wheeler and P.R. Aimone, in: Structural Intermetallics, R. Darolia, J.J. Lewandowski, C.T. Liu, P.L. Martin, D.B. Miracle and M.V. Nathal (eds.), Vol. 1, TMS, Warrendale, 1993; pp. 151-158.

6. P. Wang, G.B. Viswanathan and V.K. Vasudevan, Metall. Trans., 23A, 690-697 (1992).

7. M. Takeyama, t. Kumagai, M. Nakamura and $M$. Kikuchi, in: Structural Intermetallics, R. Darolia, J.J. Lewandowski, C.T. Liu, P.L. Martin, D.B. Miracle and M.V. Nathal (eds.), Vol. 1, TMS, Warrendale, 1993; pp. 167-176.

8. S.A. Jones and M.J. Kaufman, Acta Metall. Mater., 41, 387-398 (1993). 